\title{
Correlation of Helicobacter Pylori Infection with Acid Peptic Disorders.
}

\author{
Thavendra Jaglal Dihare ${ }^{1}$, Lamture Yashwant. R. ${ }^{2}$, Varsha Gajbhiye ${ }^{3}$, Gode Dilip ${ }^{4}$ \\ ${ }^{1}$ Asst. Professor in Surgery, J.N. Medical College Wardha, ${ }^{2}$ Professor in Surgery, J.N. Medical College Wardha, \\ ${ }^{3}$ Asso. Professor in Pharmacology, Datta Meghe Medical College, Nagpur, ${ }^{4}$ Professor in Surgery, Datta Meghe \\ Medical College, Nagpur
}

\begin{abstract}
Introduction: The acid peptic disorder is a disorder in which due to hyperacidity, there is the damage of inner lining(mucosa) of the stomach and duodenum causing various manifestations like inflammation, ulcer, etc. The acid peptic disorder is a disorder in which due to hyperacidity, there is the damage of inner lining(mucosa) of the stomach and duodenum causing various manifestations like inflammation, ulcer, etc. A major symptom of the acid peptic disorder is a pain in the abdomen typically non radiating, burning, and located at in epigastrium, Other include nausea, vomiting, dyspepsia, haemtemesis, and melena, etc. Upper gastrointestinal tract disorders are common in surgical practice. Helicobacter pylori is a common cause of acid peptic disorders. Still in literature there is a controversy still exist to question about role of Helicobacter in causing acid peptic disorders. So This study was undertaken to evaluate the correlation of H. Pylori infection with acid peptic disorders. Method: This study was a prospective observational. The duration of this study was from September 2017 to September 2019. The numbers of patients were 150. After the establishment of a clinical diagnosis of an acid peptic disorder, the patient was posted for endoscopy. $\mathrm{H}$. pylori status was determined by the rapid urease test. The data collected included the presenting complaints, clinical signs, endoscopic findings, results of rapid urease test, and histopathological examination. The presence of $\mathrm{H}$ pylori infection was correlated with symptoms, and endoscopy findings. Results: In the present study, 150 patients with upper gastrointestinal symptoms were studied It was found that the maximum number of subjects belonged to the age group 31-40 yrs. It was found that of subjects male 112 and female. It was found that maximum number of subjects had pain in epigastric region 120 cases i. e. $80 \%$ followed by symptoms nausea 75 cases ie. 50\%. about endoscopic findings 70 patients were having gastritis, 15 had a duodenal ulcer,9 patients had Duodenitis, the gastric ulcer was found in 08 patients, gastric malignancy in 02 patients and 46 patients had endoscopic normal mucosa. The highest positivity of RUT was seen in patients of duodenal ulcers $(86.66 \%)$, followed by gastritis $(82.85 \%)$ and gastric ulcer $(75 \%)$. Conclusions: Present study, we have found that there is an association of $\mathrm{H}$. Pylori infection in an acid peptic disorder like duodenal ulcer, gastric ulcer, and gastritis.
\end{abstract}

Keywords: Gastritis, duodenal ulcer, rapid urease test, dyspepsia.

\section{Introduction}

The acid peptic disorder is a disorder in which due to hyperacidity, there is the damage of inner

\section{Corresponding Author:}

\section{Dr. Lamture Y.R.}

Professor in Surgery, Surgery Department, J.N. Medical College Wardha lining (mucosa) of the stomach and duodenum causing various manifestations like inflammation, ulcer, etc. A major symptom of the acid peptic disorder is a pain in the abdomen typically non radiating, burning, and located in epigastrium, Other include nausea, vomiting, dyspepsia, haemtemesis, and melena, etc. Upper gastrointestinal diseases are one of the common entities in surgical practice. A disease of the stomach and duodenum range from a benign disease like gastritis, peptic ulcer diseases which are usually having a self- 
limiting although a prolonged course with a potentially dangerous complication like perforation with its attendant's peritonitis both chemical and bacterial, to malignant diseases like carcinoma of the stomach. The upper gastrointestinal disease forms a major part of the total number of patients attending the outpatient clinic for gastrointestinal disorders. The treatment of peptic ulcers has been based on Schwartz dictum "No acid, no ulcer". The gastric acid has dominated the approach to the diagnosis and treatment of peptic ulcer disease. Marshall and Warran (1984) published a paper entitled unidentified curved bacilli in the stomach of patients with gastritis and peptic ulceration first time in history. These investigators identified a spiral-shaped flagellated organism associated with peptic ulcer originally referred to as campylobacter pyloride. The organism is now known as Helicobacter Pylori ${ }^{1}$. H.Pylori is a gramnegative organism resides in the stomach of human and other animals,affecting half of the population of world ${ }^{2}$. H. Pylori is a common cause of peptic ulcer of stomach and duodenum leading to clinically present as recurrent abdominal pain. It is corelated with around $90 \%$ of duodenal ulcers and $80 \%$ of gastric ulcers, major cause of morbidity. Mortality associated however is low but can result in chronic illness leading to significant manpower loss. It can also cause lymphoma and gastric carcinoma ${ }^{3}$. Present understanding about the aetiology of peptic ulcer disease, gastric cancer, and dyspepsia is under evolution. The invention of Helicobacter pylori as a infective aegent change our method to treat and diagnose it. Human beings are the only reservoir for Helicobacter Pylori. Direct transmission from person to person occurs via saliva and feces and infection also through contact with contaminated water ${ }^{4}$. The Nobel prize in physiology or medicine for the year 2005 was awarded to both J. Robin warren and Barry J Marshall. These Nobel winners made a astonishing and unbelievable invention that chronic inflammation in stomach and duodenum (Gastritis, gastic and duodenal ulcer), is due to an infection by bacterium H. Pylori. Many tried to disprove it ${ }^{5}$. As recent trend of decrease evidence of peptic ulcers was observed from last 40 years. The discovery of Helicobacter Pylori had a further major impact on the incidence of ulcer ${ }^{6}$. So This study was undertaken to evaluate the correlation of $\mathrm{H}$. Pylori infection with acid peptic disorders.

\section{Method}

The present study was undertaken in the department of surgery, Jawaharlal Nehru Medical College,
Wardha in collaboration with Datta Meghe Medical College Hingana, Nagpur, Datta Meghe Institute of medical science (DMIMS), Sawangi, Meghe, Wardha, Maharashtra India. This study was a prospective observational. The duration of this study was from September 2017 to September 2019. The numbers of patients were 150 . The sample size was calculated as per formula was around 134 Hence 150 sample size was sufficient $(\mathrm{N}=2(\mathrm{Z} \alpha+\mathrm{Z1}-\beta) 2 \sigma 2 / \Delta 2)$. The present study was carried out on the patients attending surgical OPD as well as the surgical ward from September 2017 to September 2019 in the tertiary center. We selected 150 patients having gastrointestinal complaints. The complaints were a pain in the abdomen, usually in the epigastric region, dyspepsia, nausea, vomiting, haemtemesis, melena, etc. In personal history, the habit of tobacco chewing, cigarette smoking, alcohol consumption, and appetite were included. Detail history of patients was taken with regards to the symptom, their duration, and severity, other complaints, drug history. A thorough clinical examination and routine haematological examination of patients was done. After the establishment of a clinical diagnosis of an acid peptic disorder, the patient was posted for endoscopy. H. pylori status was determined by the rapid urease test and histopathological examination.

Inclusion Criteria: Patients between 15-60 years were having symptoms of the acid peptic disorder.

Exclusion Criteria: Patients taking antibiotics and bismuth compounds or omeprazole 4 wks before endoscopy. Pregnancy.

Detail of procedure followed. Patients with clinical symptoms of APD were advised to attend the Gastroscopy clinic. The patients were kept nil orally at night and were advised to attend endoscopy clinic early in the morning Endoscopy was performed with Fujinon Gastroduodenoscope after obtaining informed consent. Esophagogastroduodenoscopy of each patient was done under surface local anesthesia with $4 \%$ Xylocaine viscous. Findings were noted and biopsies from the antrum and suspicious lesions were taken. Out of biopsies, one was subjected for a rapid urease test and the second biopsy specimen was used for histopathological examination. Endoscopic findings were recorded as gastritis, duodenal ulcer, gastric ulcer, gastric carcinoma, and endoscopically normal mucosa as per standard criteria. 
Data Collection: The data collected included the presenting complaints, clinical signs, endoscopic findings, results of rapid urease test, and histopathological examination.

Statistical Analysis: The presence of $\mathrm{H}$ pylori infection was correlated with symptoms, and endoscopy findings .this calculation was derived using SPSS 17.0 statistical software.

Ethical approval for the study was obtained from the ethics committee of DMIMS University.

\section{Results}

In the present study, 150 patients with upper gastrointestinal symptoms were studied It was found that the maximum number of subjects belonged to the age group $31-40$ yrs. i.e. $26.66 \%$ followed by age group 21-30 yrs. ie $22.66 \%$. It was found that of subjects male 112 and female 38.M: F 2.94:1

\section{Table 01: Symptoms profile of patients}

\begin{tabular}{|l|c|c|}
\hline Symptom & No. of cases & Percentage \\
\hline Pain in epigastric region & 120 & 80 \\
\hline Nausea & 75 & 50 \\
\hline Vomiting & 42 & 28 \\
\hline Dyspepsia & 46 & 30.66 \\
\hline Haemtemesis & 15 & 10 \\
\hline Meleana & 09 & 06 \\
\hline
\end{tabular}

Table 3 shows the symptoms profile of study subjects. It was found that maximum no. subjects had pain in epigastric region 120 cases i. e. $80 \%$ followed by symptoms nausea 75 cases ie. $50 \%$.

Table 02: Endoscopic findings in patients with acid peptic disorder

\begin{tabular}{|l|c|}
\hline Endoscopic findings & No. of cases \\
\hline Gastritis & 70 \\
\hline Duodenitis & 09 \\
\hline Duodenal ulcer & 15 \\
\hline Gastric ulcer & 08 \\
\hline Gastric malignancy & 02 \\
\hline $\begin{array}{l}\text { Endosc. Normal mucosa but clinically } \\
\text { symptoms of APD }\end{array}$ & 46 \\
\hline & 150 \\
\hline Total & \\
\hline
\end{tabular}

70 patients were having gastritis, 15 had a duodenal ulcer, 9 patients had Duodenitis, the gastric ulcer was found in 08 patients, gastric malignancy in 02 patients and 46 patients had endoscopic normal mucosa.

Table 3. Result of Rapid Urease Test in Acid Peptic Disease

\begin{tabular}{|c|l|c|c|c|}
\hline Sr.No. & Diagnosis & No. of pts. & RUT positive & Percentage \\
\hline 1. & Gastritis & 70 & 58 & 82.85 \\
\hline 2. & Duodenitis & 09 & 05 & 55.55 \\
\hline 3. & DU & 15 & 13 & 86.66 \\
\hline 4. & GU & 08 & 06 & 75 \\
\hline 5. & GM & 02 & 01 & 50 \\
\hline 6. & Endo. Normal but clinically s/o APD & 46 & 16 & 34.78 \\
\hline
\end{tabular}

The highest positivity of RUT was seen in patients of duodenal ulcers $(86.66 \%)$, followed by gastritis $(82.85 \%)$ and gastric ulcer $(75 \%)$.

\section{Discussion}

In this study, 150 patients (112 men and 38 women), within the range of 15 to 72 years, with symptoms suggestive of acid peptic disorder, were included. In 
our study, we found that acid peptic disorder was more common in the age group $31-40$ years $(26.66 \%$ cases). Followed by $21-30$ years $(22.66 \%$ cases $)$ and $41-50$ years $(17.33 \%$ cases $)$.

In similar studies following results were seen:

Table 4: comparison with previous studies:

\begin{tabular}{|l|c|c|}
\hline Study & Year & $\begin{array}{c}\text { Mean age of patients } \\
\text { with APD }\end{array}$ \\
\hline B Sharma $^{7}$ & 2006 & 32.8 \\
\hline C. Rekha & & 40.89 \\
\hline GM Malik et al $^{9}$ & 1999 & 34.80 \\
\hline J. Yakoob et al & & 40.89 \\
\hline Endale Tadesse et al $^{11}$ & 2014 & 36 \\
\hline Present study $^{10}$ & 2019 & 38.48 \\
\hline
\end{tabular}

Sex wise distribution: In our study, we found that Acid peptic disorder was more common in males as compared to females. M: F ratio was 2.94: 1

Table 5: Endoscopic Finding

\begin{tabular}{|l|c|c|c|}
\hline Study & Gastritis & $\begin{array}{c}\text { Duodenal } \\
\text { ulcer }\end{array}$ & $\begin{array}{c}\text { Gastric } \\
\text { ulcer }\end{array}$ \\
\hline In our study & $82.85 \%$ & $86.66 \%$ & $75 \%$ \\
\hline Yakoob et al (2005) ${ }^{10}$ & $65 \%$ & - & - \\
\hline J M Pajures (2005) $)^{12}$ & $88 \%$ & $90 \%$ & $80-90 \%$ \\
\hline Vandana Berry (2006) $^{13}$ & - & $90 \%$ & $80 \%$ \\
\hline Richard G (2005) & - & $95 \%$ & $80 \%$ \\
\hline
\end{tabular}

In our study, we found a maximum number of duodenal ulcer cases $(86.66 \%)$ followed by gastric ulcer cases $(75 \%)$ and gastritis $(82.85 \%)$.

Symptom Analysis: In our study, we found epigastric pain, nausea, dyspepsia, and vomiting as the most common symptoms associated with the acid peptic disorder as detected on endoscopy(see table 3).

Vandana Berry ${ }^{\mathbf{1 3}}$ in their study found that most common symptoms are epigastric pain, nausea, vomiting, and dyspepsia

Tom Richard Okello (2006) $)^{14,15}$ in their study found that the most common symptoms are a pain in the epigastric region, dyspepsia, haematemesis recurrent abdominal pain, vomiting, and miscellaneous. The findings in the present study are comparable to these studies
Table 6: Comparison with previous studies for diagnosis

\begin{tabular}{|l|c|c|}
\hline Name of the study & Year & RUT \% \\
\hline Sivaprakash et al $^{15}$ & 1994 & 38.7 \\
\hline Maimomma et al $^{2}$ & 1994 & 65.8 \\
\hline B Sharma $^{7}$ & 2006 & 59 \\
\hline Our study & 2019 & 66 \\
\hline
\end{tabular}

In our study in patients with acid peptic disorder rapid urease test was positive in 99 patients $(66 \%)$.

\section{Conclusion}

The present study was carried out on the patients attending surgical OPD as well as admitted patients inward who had clinical symptoms suggestive of acid peptic disease from September 20017 to September 2019 in the tertiary care center. A total of 150 patients were studied and advised to attend the Gastroscopy clinic.

1. The symptoms of acid peptic disorder were more in 31-40 years followed by 21-30 years.

2. In our study, we have found there was male predominance with male to female ratio of 2.94:1.

3. In our study, we found that there was an association of symptoms of acid peptic disease with $\mathrm{H}$. Pylori infection. Pain in the epigastric region $(80 \%)$ and nausea $(50 \%)$ were the most frequent symptoms associated with $\mathrm{H}$. pylori infection followed by dyspepsia (30.66\%).

4. In our study, we have found that there is a strong association between $\mathrm{H}$. Pylori in duodenal ulcer $(86.66 \%)$, gastric ulcer $(75 \%)$, and gastritis $(82.85 \%)$.

5. In our study, we have found that the rapid urease test for H. Pylori was positive in $66 \%$ of patients.

From the study we could draw the following conclusion:

1. In our study, we have found that the incidence of Helicobacter infection in acid peptic disorder is $66 \%$.

2. In our study, we have found that there is an association of $\mathrm{H}$. Pylori infection in an acid peptic disorder like duodenal ulcer $(86.66 \%)$, gastric ulcer (75\%), and gastritis $(82.85 \%)$.

Ethical Clearance: Taken from institutional ethics committee. 
Source of Funding: Self.

\section{Conflict of Interest: Nil.}

\section{Reference}

1. Adrienne $Z$ et al. Update on H.Pylori. Journal of American Family Physician 2007;75:351-8

2. Sengupta $\mathrm{S}$ et al. Helicobacter pylori in duodenal ulcer disease and its eradication. Indian $\mathrm{J}$ Med Microbiol 2002;20:163-4

3. Kidd $\mathrm{M}$ et al. A Century of Helicobacter Pylori, Digestion 1998;59:1-15

4. Warren $\mathrm{J}$ et al. Unidentified curved bacilli on gastric epithelium in active chronic gastritis. Lancet 1983 Jun 4;1(8336):1273-1275

5. Press Release the 2005 Nobel Prize on physiology or Medicine third October 2005.

6. Groenen $\mathrm{M}$ et al. The incidence of duodenal ulcer and gastric ulcer in the western population. Can $\mathrm{J}$ Gastroenterol. 2009; 23(9): 604-608.

7. Sharma B et al. Relationship of Smoking with H. Pylori Incidence in Non-Ulcer Dyspepsia Patients JIACM 2006;7(1),22-4.

8. Rekha $\mathrm{C}$ et al. Role of H.Pylori, hyperammonemia in subclinical hepatic encephalopathy in cirrhosis of the liver. Indian journal of clinical biochem.;2007/22 (2)136-139.
9. Malik $\mathrm{G}$ et al. H. Pylori infection in endoscopy biopsy specimens of gastric antrum: laboratory diagnosis and comparative efficacy of three diagnostic tests. Diagnostic and therapeutic endoscpy 1999,6,25-29.

10. Yakoob, J et al. Role of RUT and histopathology in the diagnosis of H.Pylori infection in developing country BMC Gastroentrol 2005;5:38.

11. Tadesse E et al. Seroprevalence of Helicobacter pylori infection and its related risk factors in symptomatic patients in southern Ethiopia. BMC Res Notes. 2014; 7: 834.

12. Pagares $\mathrm{J}$ et al. H.Pylori: its discovery and relevance for medicine. Rev Esp Enferm Dig 2006;98(10):770-85.

13. Berry $\mathrm{V}$ et al. Rapid urease test to diagnosis H.Pylori infection JK Science. 2006,8 (2):85-88.

14. Lynch R., Helicobacter pylori and Ulcers, Originally published in The ASIP Bulletin, 2005; 8(1).

15. Rao S. Indigenous, simple, sensitive, and cost effective urease test in the diagnosis of H.pylori for the developing world. Indian J Med Microbiol 1994;12:111-115

16. Guariso $\mathrm{G}$ et al. Update on Peptic Ulcers in the Pediatric Age. Hindawi Publishing Corporation, Ulcers. 2012, Article ID 896509, 9. 